\title{
DESCRIPTION OF THE VENTILATING FAN AT THE ABERCARN COLLIERIES.
}

The mode of ventilation that is still generally used in the collieries of this country is the old furnace ventilation, where the required current of air through the mine is maintained by the rarefaction of the column of air in the ascending shaft, by means of a large fire kept constantly burning at the bottom of the shaft. In Belgium and France, on the contrary, this plan is almost superseded by the use of machinery to maintain the eurrent of air; as the furnace ventilation, althongh possessing the important advantages of great simplicity and freedom from liability to derangement from disturbing causes, has some serious objections and deficiencies, and in some cases becomes so imperfect a provision for ventilation as to render a better system highly desirable and even necessary.

The author of the present paper, having occasion to ventilate the workings in some extensive and very fiery coal seams recently won at Abercarn in South Wales, under circumstances where the furnace ventilation could not be applied, after carefully collecting every accessible information as to the ventilating machines used in Great Britain and on the Continent, came to the conclusion that a plan of machine proposed for the purpose some years since by Mr. James Nasmyth would be the most suitable and effective. After consultation with Mr. Nasmyth, it was resolved to test the principle and plan by actual practice; and the ventilating fan described in the present paper was made at Patricroft by Mr. Nasmyth, and is erected and now working at the Abercarn Collieries.

The general arrangements of the top of the shaft and the ventilating fan are shown in Figs. 1 to 4, Plates 88 and 89; Figs. 1, 2, and 3 are vertical sections, showing the air valves at the mouth of the pit, and the passage connecting the fan with the pit; Fig. 4 is a sectional plan of the pit and fan.

Fig. 5, Plate 90 , is a side elevation of the fan and engine, to a larger scale; and Fig. 6 a vertical section of the fan.

The fin AA, Fig. 6, is $13 \frac{1}{2}$ feet diameter, with 8 vanes, each 3 feet 6 inches wide and 3 feet long. It is fixed on a horizontal shaft $B, 8$ feet 
7 inches in length from centre to centre of the bearings, which are 9 inches long by $4 \frac{1}{2}$ inches diameter. The vanes are of thin plate iron, and carried by forked wrought iron arms secured to a centre disc $\mathrm{C}$ fixed upon the shaft $B$. The fan works within a casing DD consisting of two fixed sides of thin wrought plate, entirely open round the circumference and counected together by stay rods; the sides are 3 inches clear from the edges of the vanes, and have a circular opening 6 feet diameter in the centre of each, from which rectangular wrought iron trunks $\mathrm{EE}$ are carried down for the entrance of the air, the bearings for the fan shaft $B$ being fixed in the outer sides of these trunks, which are strengthened for the purpose by vertical cast iron standards $F$ bolted to them and resting upon the bottom foundation stone $G$.

The two air trunks EE join together below the fan, as shown in Fig. 1, and communicate with the pit $\mathrm{H}$ by means of a horizontal tunnel $\mathrm{I}$, which enters the pit at 21 feet depth from the top.

The fan is driven by a small direct-acting non-condensing engine $K$, which is fixed upon the face of one of the vertical cast iron standards $F$, and is connected to a crank on the end of the fan shaft $B$. The steam cylinder is 12 inches diameter and 12 inches stroke, and is worked by steam from the boilers of the winding engine of the pit, at a pressure of about 13 lbs. per square inch. The eccentric $L$ for the slide valve is placed just inside the air trank $\mathrm{E}$, and works the valve throngh a short weigh shaft $\mathbf{M}$ with a lever on the outside.

The pit H, Fig. 4, is of an oval form, 10 feet by 18 feet, and divided near the centre by a timber brattice $\mathrm{N}$, the one side forming the upeast shaft and the other the downcast. Both of these are used for winding, and the cages $\mathrm{O}$, in which the trucks, \&c., are brought up, work between guides fixed to the timbering of the pit. The pumps $\mathrm{P}$ are placed in the downcast shaft.

In order to allow of the upeast shaft being used for winding, the top is elosed by an air valve $R$, which is formed by simply boarding up the underside of the ordinary guard upon the mouth of the shaft, leaving only the hole in the centre through which the chain works. This air valve $R$ is earried up by the cage $\mathrm{O}$ on arriving at the top of the shaft, as in Fig. 3, and then drops down again flat upon the opening when the cage is again lowered, as in Fig. 2. During the time that the valve is lifted, its place is 
occupied by the close bottom of the cage $O$, which nearly fills the rectangular opening left at the top of the shaft. By this simple means it is found practically that a complete provision is made for keeping the top of the upcast shaft closed, and maintaining a uniform current of air up the shaft; for the leakage of air downwards through the top whilst the cage is in the act of opening or closing the air valve, and through the small area that always remains open, is found to be quite immaterial, and the surplus ventilating power of the fan is amply sufficient to provide against it.

In the original construction a more perfect air valve was supposed to be requisite, and was provided by the inclined flaps SS, which are fixed just above the horizontal tunnel $I$. These are fitted closely together, leaving only a small opening in the centre for the chain to pass through, and were intended to be opened by the ascending cage coming in contact with them, closing again directly by means of balance weights before the air valve $R$ at the top of the shaft was opened, so as to preserve a thorough closing of the top of the shaft. The flaps were to be opened again by a lever from the top to allow the cage to descend. However, it was found on trial that the valve $\mathrm{R}$ at the top was amply sufficient; and consequently, although the other valves $\mathbf{S}$ were also provided, they have never been put into use.

The total depth of the pit is nearly 300 yards, and at a depth of 120 yards a split of air is taken off, and coursed through workings from which coal and fire clay are got; the larger portion of the air descends to the bottom of the pit, and is there split into many courses, to work two separate seams of coal and a vein of ironstone. The total length of road laid with plates or rails in the workings is about 7 miles, and the working faces amount to nearly double that distance. The longest distance that is. traversed by any single course or split of air in passing from the downcast. to the upcast shaft is nearly 2 miles. The quantity of materials raised from the pit is about 500 tons daily.

The speed at which the ventilating fan is usually worked is about 60 revolutions per minute, giving a velocity at the circumference of the fan of 2545 feet per minute; 45000 cubic feet of air per minute are then drawn through the mine, nearly one third of which ventilates the upper workings, and the rest passes through the lower workings. 
Table I (appended) gives the results of a series of experiments made with this ventilating fan under the direction of the author by Mr. R. S. Roper, showing that the quantity of air delivered at the velocities of 60 and 80 revolutions of the fan per minute is 45000 and 56000 cubic feet per minute, with a velocity of current of 782 and 1037 lineal feet per minute respectively, or about 9 and 12 miles per hour; and the degree of vacuum or exhaustion in the upcast shaft is $\cdot 5$ and $\cdot 9$ inch of water respectively.

In these experiments the mode adopted for ascertaining the velocity of the air currents was by calculation from the difference of pressure, as observed by méans of a carefully constructed vacuum gange, the result being checked by the anemometer and by the time of passage of the smoke of powder fired at fixed distances by means of wires from a voltaic battery at the top of the shaft.

The working velocity of the fan is readily and instantly regulated by means of a throttle valve in the steam pipe of the engine, which is under the control of the man in charge of the working of the pit, and is adjusted according to the requirements of the ventilation arising from changes in the atmospheric pressure and in the quantity of gas in the workings. It has been found that a velocity of about 50 to 60 revolutions per minute gives the best amount of ventilation, and that beyond 80 revolutions the current of air is too strong to allow of the lamps being kept alight in the workings.

This ventilating fan has been now in constant work for two years, night and day, without once stopping for repairs of any kind, and is in as good working order as when first started; there appears to be nothing to get out of order about the machine on account of the simplicity of its construction, and no reason to anticipate any failure. The engine is made very simple in construction, with large and durable wearing surfaces, and the steam cylinder is fitted with a solid metal piston to prevent any occasion for stopping to adjust the packing. The whole cost of the steam power for working the fan is so insignificant that a little leakage of steam is quite immaterial. The complete arrangement would be to have a second duplicate fan fixed complete, and ready to be set to work at any moment if the first was stopped, or to work in conjunction with it on any emergency requiring greatly increased ventilation; though from the experience of the present fan it has not appeared requisite to take any such precnution. 
In ease of putting up another fan for a similar purpose, the author would adopt one of still larger diameter, probably 21 feet diameter, and running at a slow speed, which he considers would be preferable and still more economical in power. The construction of the casing of the fan he would propose to make of a simpler and less expensive description, using only thin brick walls for the sides and the air trunks. The whole expense would then be very inconsiderable, even for a complete pair of the ventilating fans.

The ventilating fan has a very important advantage over the furnace ventilation, in the power it affords of suddenly increasing the current of air to a great extent in any emergency; whilst with the furnace any increase is very slow in action and limited in extent, and cannot be effected from the surface of the ground.

Another advantage is the coolness and freshness of the upeast shaft, which can be used for the passage of the men as freely as the downcast shaft, being free from the heat and smoke of the furnace ventilation.

There is also no risk of explosion from the access of gas to the furnace fire; and in the first opening of a fiery seam, as in the present case at Abercarn, a furnace could not have been safely lighted until after a longr delay for drainage of the gas, owing to the sudden and extensive liberation of gas, and even then it would have been attended with considerable difficulty and danger; but with the help of the fan all delay and danger was avoided, and the workings commenced immediately on reaching the seam.

A bratticed shaft was the only plan practicaule in the present case: on account of the great difficulty of sinking deep through the rock; whish was of remarkable hardness; and in such cases the furnace ventilation is very objectionable on account of the constant leakage caused by the diying of the timber of the brattice from the effects of the heat of the fire, and the corroding action of the sulphurous vapours of the furnace smoke.

By employing the suction in place of the blowing actiony and haring ta fan of large diameter, great exhausting power is obtained without hequithing a high velocity of rotation; the circumference of the fan casebeing left open allows the air to be expelled all round with perfect freedom; and the dritril. diaphragm plate on the fan spindle prevents the opposite ourretrts of air entering at each side from impeding each other. The simple thamer of driving, by an engine acting direct by a crank on the fain spidtlle, saves the 
necessity for intermediate gearing; and by having the fan on the surface of the ground exposed to sight, its action and rate can be seen at all times to be effective, whilst it is safe from the chance of any damage arising from an explosion, were one to occur.

In the pit at Abercarn the quantity of gas is so serious that safety lamps are now used exclusively throughout the workings, and not a single naked light is allowed, except at the two stations near the shaft where the safety lamps are lighted and locked up. Several very slight explosions have occurred, but not any at all serious in their consequences, except one, which may be mentioned as a useful example of the great practical value of a means of suddenly producing a greatly increased current of ventilation, in preventing loss of life from the result of explosion. In this instance, which occurred about October, 1855, one of the men took a naked candle into a stall in which fire damp had accumulated in the lower workings, at about 150 yards distance from the shaft. An explosion ensued, which was heard by the author, who was at the top of the shaft at the time; and he instantly turned the steam full on to the engine of the fan, which immediately increased the speed of the fan to nearly double its rate, and caused such a sudden increase in the velocity of the current of ventilation, that the after damp resulting from the explosion was carried past the men in the workings so quickly that they escaped all serious injury, so momentary, was their exposure to its effects. But if the ordinary velocity of current only had been maintained, some of these men could not have escaped with their lives. The man who caused the explosion was severely burnt, but recovered from the injury.

Almost immediately after turning on the steam to the fan, a shower of black particles was thrown out of the fan, which would be the result of the explosion, being the fine particles of carbon, liberated as light flaky soot from the decomposition of the earburetted hydrogen by the explosion. This is commonly but incorrectly called "coal dust," and is always the result of an explosion; and in the author's opinion this is the cause of the fatal effect of the after damp, from the accumulation of the minute solid particles upon the lungs, and not the exposure to the carbonic acid and nitrogen resulting from the combustion of the gas and air. This opinion is confirmed by the result of examiriation of the lungs of men killed by mine explosions, which are found to be loaded with these black solid particles. It has been observed 
frequently that men can live for some time in the after damp following a mine explosion, if they take the precaution to cover their mouths and nostrils completely with a handkerchief, so as to sift the air they breathe and prevent these floating particles of carbon from entering the lungs; and this precaution is enjoined in the rules of several mines, to prevent breathing the "coal dust" as it is termed. The author has known a case, where a miner, named John Hall, now living at Aberearn, got through a distance of half a mile filled with the after damp by taking this precaution, and escaped with safety to the shaft.

One of the most explosive mixtures of gases that can be produced in a coal mine is in the proportion of 5 volumes of carburetted hydrogen and 40 volunes of atmospheric air. When this mixture is exploded the results are 2 volumes of vapour of corbon, 3 volumes of carbonic acid gas, 10 volumes of vapour of water, and 32 volumes of nitrogen gas. After the explosion the carbon assumes the form of light flaky soot, which is very finely distributed throughout the air. Table II. illustrates the manner in which the writer believes that the decomposition and combinations accompanying the explosion take place.

A similar ventijating fan to that above described has been since erected by Mr. Nasmyth at Skiar Sping Colliery, near Elsecar, which is working with complete success ; it is of rather larger size than the one at Abercarn, being 15 feet diameter and 4 feet 3 inches wide in the vanes, and is worked at 80 revolutions per minute by the steam from a pumping engine boiler at 15 lbs. per square inch. The result is a thoroughly efficient ventilation of the workings, completely under control at the surface of the ground, and maintained at an expenditure of fuel extremely small as compared with that required for the ordinary furnace ventilation. 
TABLE I.

Synopsis of Experiments on Fan Ventilation.

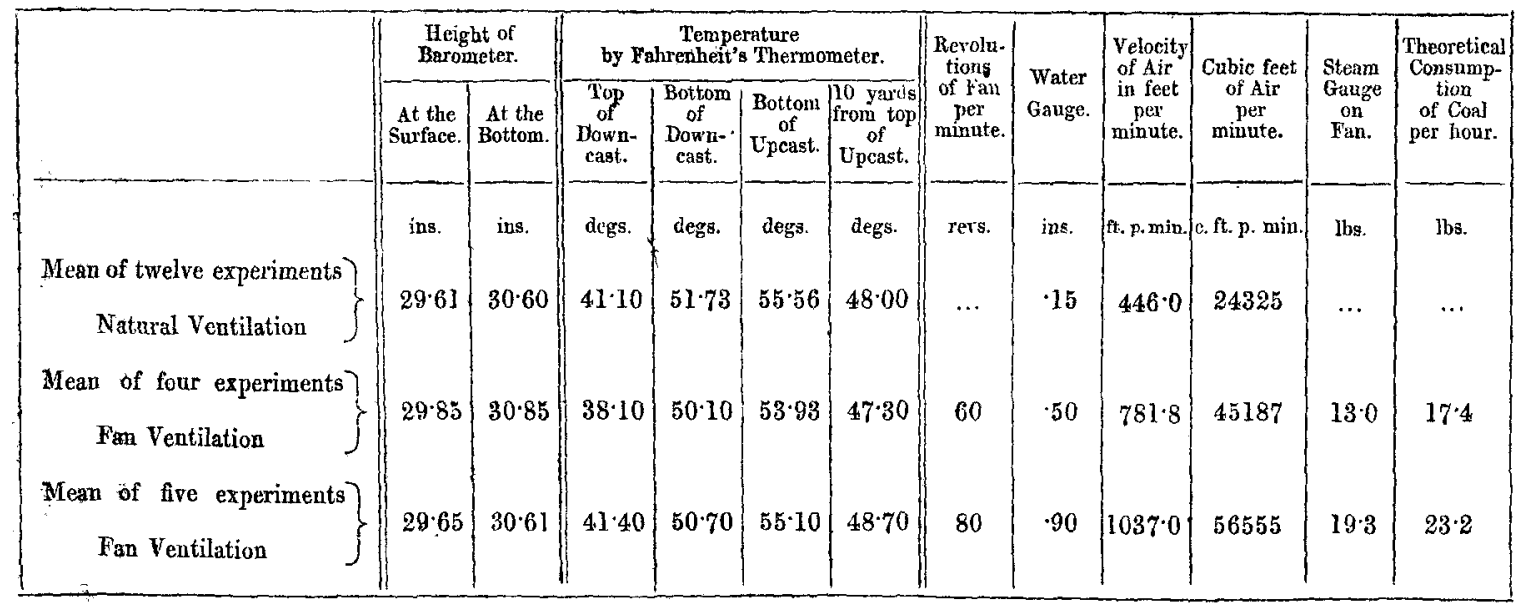


TABLE II.

Table illustrating a Mine Explosion.

\begin{tabular}{|c|c|c|c|c|c|}
\hline \multicolumn{2}{|c|}{ BEFORE EXPLOSION. } & \multicolumn{4}{|c|}{ AFTER EXPLOSION. } \\
\hline $\begin{array}{c}5 \text { vols. of } \\
\text { Carburetted } \\
\text { Hydrogen. } \\
5 \mathrm{CH}_{2}\end{array}$ & $\begin{array}{c}40 \text { vols. of } \\
\text { Atmospheric } \\
\text { Air. } \\
80+32 \mathrm{~N}\end{array}$ & $\begin{array}{c}2 \text { vols. of } \\
\text { Vapour of } \\
\text { Carbon. } \\
2 \mathrm{C}\end{array}$ & $\begin{array}{l}3 \text { vols. of } \\
\text { Carbonic } \\
\text { Acid Gas. } \\
3 \mathrm{CO}_{2}\end{array}$ & $\begin{array}{c}10 \text { vols. of } \\
\text { Vapour of } \\
\text { Water. } \\
10 \mathrm{HO}\end{array}$ & $\begin{array}{c}32 \text { vols. of } \\
\text { Nitrogen } \\
\text { Gas. } \\
32 \mathrm{~N}\end{array}$ \\
\hline $\begin{array}{l}\text { C } 1 \text { vol. } \\
\text { C } 1 \text { vol. }\end{array}$ & & $\begin{array}{l}\text { C } 1 \text { vol. } \\
\text { C } 1 \text { vol. }\end{array}$ & & & \\
\hline C 1 vol. & $\left\{\begin{array}{lll}0 & \frac{1}{3} & \text { vol. } \\
0 & \frac{1}{2} & \text { vol. }\end{array}\right\}$ & & $\mathrm{CO}_{2} 1$ vol. & & \\
\hline C I vol. & $\left\{\begin{array}{ll}0 & \frac{1}{2} \\
0 & \frac{1}{2} \text { vol. }\end{array}\right\}$ & & $\mathrm{CO}_{2} 1$ vol. & & \\
\hline C I vol. & $\left\{\begin{array}{lll}0 & \frac{1}{2} & \text { vol. } \\
0 & \frac{1}{2} & \text { vol. }\end{array}\right\}$ & & $\mathrm{CO}_{2} 1$ vol. & & \\
\hline H l vol. & O $\frac{1}{2}$ vol. & & & HO I vol. & \\
\hline H 1 rol. & O. $\frac{1}{2}$ vol. & & & HO 1 voł. & \\
\hline H 1 vol. & O t vol. & & & HO 1 vol: & \\
\hline H 1 vol. & O $\frac{1}{2}$ vol. & & & HO 1 voli & \\
\hline H 1 vol. & O $\frac{1}{2}$ vol. & & & HO 1 rol. & \\
\hline H I vol. & O $\frac{1}{2}$ vol. & & & HO I vol. & \\
\hline H 1 vol. & O $\frac{1}{2}$ vol, & & & HO I vol. & \\
\hline H 1 vol. & O $\frac{1}{2}$ vol. & & & HO I vol. & \\
\hline H I vol. & O t yol. & & & HO 1 vol. & \\
\hline H 1 vol. & O $\frac{1}{2}$ vol. & & & HO 1 vol. & \\
\hline & N 32 vols. & & & & N 32 vols. \\
\hline
\end{tabular}

The chemical equivalent of oxygen by volume, or the combining volume of oxygen, being a half-vol., the 8 vols. of oxygen which are in mechanical mixture in the air before explosion represent the 16 equivalents or 16 !half-vols. which are in chemical combination with the carbon and hydrogen after exptosion. 
The Charnmas thought a more interesting and important paper could not have been brought before the Institution, for every one acquainted with the working of collieries must be aware of the great value of thoroughly efficient ventilation, and the danger and serious risk of life attending any imperfection in the system. Only a few months previously an explosion had occurred in Wales, by which more than a hundred persons had been killed in one pit, showing the necessity of adopting some efficient system of ventilation, that would not be liable to derangement from aceidental causes; and the method now deseribed was certainly a very simple and mechanical way of accomplishing this object. Several attempts at mechanical ventilation had been made previously, but did not appear to have met with mueh success in actual adoption : mechanical means had been tried, he believed, more in Wales than elsewhere, because the coal in that district contained such a large proportion of explosive compounds. He enquired what were the essertial points of difference in the previous methods from the one now described.

Mr. ROGERs replied that there was nothing new in the principle of ventilation by purely mechanical means; the same principle had been in use centuries ago on the continent, although of comparatively recent introduction into this country. The old German miners had used an inverted tub, placed in water, and worked up and down by a lever, with an air valve at the top opening inwards, the fresh air being alternately drawn into the tub and expelled along an air main conducting it into the workings. This rude contrivance had been recently improved and the plan carried out on a large scale in Struve's ventilator, in which the inverted air vessels were like large gasometers; but the apparatus was expensive and proved troublesome in working, Rotary ventilators, acting on the principle of the screw, had been tried in some cases; and the fan had also been applied, but without suceess, in consequence, he considered, of a want of mechnnical knowledge on the part of those who had sought to adopt this method of ventilation. The need of sound mechanical applications in carrying out improvements of this nature formed his principal reason for bringing the present subject before the Institution, with the view of drawing attention to its importance.

The fan at Abercarn had proved completely successful, and he was not aware that any really effeetive machine had been prochuced previonsly; but the subsequent one at Skiar Spring Colliery was still better, and experience wonld no doubt lead to yet farther improvements, particularly in a still 
farther increase of the diameter of the fan. In some of the early attempts the air was foreed down the pit by a blowing fan, which was beginning at the wrong end of the process; and another mistake that had been made was that the area of the branch air passages was too small at the paint of taking off the air, causing a serious waste of power and a cleck to the current in passing the contracted parts. In Mr. Nasmyth's fin the simple directacting engine was an important feature, together with the compact arrangement of the machinery, requiring no foundation but the fan case itself, and giving no trouble in keeping it in repair. The engine was capable of driving the fan at 100 to 120 revolutions per minute if requisite in an emergency, but the ordinary speed was 50 or 60 revolutions per minute. This fan had been two years in constant work, without requiring any repair, and appeared in as good order now as at first starting; the cost of working, as compared with the old imperfect furnace ventilation, was remarkably small, the fan saving certainly $9-10$ ths of the fuel consumed by the ordinary ventilating furnace. The efficiency of the air valve covering the top of the pit was an unexpected result, and simplified the construction of the apparatus considerably. It had been thought originally that two air valves would be required, to prevent loss by drawing in air direct from the top of the pit, and double valves had consequently been provided; but this provision was found unnecessary, as it appeared that a column of air of so great length, extending over 12 or 15 miles through the mine, when once set in motion, was not perceptibly affected by a slight check at the end of its course, and was not disturbed by the passage of the eage in and out of the month of the pit; the simple flat door at the top accordingly answered the purpose completely. In the erection of subsequent fans the construction might be farther simplified by the substitution of thin stone or .brick walls on each side of the fan, in place of the present iron easing, with the advantage of cheapness and facility for renewal or repair.

The Chairman observed that the plan now described appeared to to be far superior to the ordinary system of furnare ventilation, in which a layge furnace was kept burning at the bottom of the shaft, so as to rarefy the air and make the requisite draught up the shaft to draw the current of air through the mine. Such a.method was unavoidably attended with coptinual variations in the current of air through the workings, as the fires fluctuated noeovding to the brightness or dullness of buming at different times, and the ventilation was dizectly, affected, by ixregularities, in keeping up the 
fires and variations in the state of the atmosphere. The use of jets of steam for ventilation, proposed by Mr. Gurney, had recently been in favour, the steam acting in the same manner as the blast in the chimney of a locomotive engine; he enquired what was the general result of this plan, and whether it was now in regular work.

Mr. Rogers thought the employment of steam jets must always be an imperfect and expensive mode of applying stean power for ventilation; it was much preferable to apply the steam direct to work a fan, by which means a low pressure of sterm could be made fully available. He did not think the plan of steam jets was continued in practical use; one serious objection to it, that was experienced when tried on a large scale, was the constant shower of water caused by condensation, from the large quantity of steam thrown into the air shaft.

Mr. Hawkes asked what degree of vacumn in inches of water was obtained by the fan ventilation, and how the velocity of the air had been estimated. From $\frac{1}{2}$ inch to $\frac{3}{4}$ inch of water was, he had found, the ordinary vacuum oltained in stationary engine chimneys.

Mr. Rogers had found in his own experiments from $\frac{x}{2}$ inch to 1 inch of water pressure, according to the speed of the fan; he had tried the vacuum by means of a water gauge, and had also estimated the velocity of the air by Dr. Hutton's theoretical calculations. The results had been checked by Biram's and other anemometers, and had been found to agree very well. A third test had been tried by firing powder at measured distances in the workings by means of a voltaic battery at the surface, the time of passage. of the powder smoke to the surface being noted by a watch.

Mr. HAw KES asked what amount of vacuum was obtained in the ordinary furnace ventilation of collieries.

The Charmman said that the information on this point was very imperfect, from the uncertainty about the experiments; he supposed the vacuum was generally below 1 inch of water, perhaps considerably less : but in large deep mines a vacuum of as much as 2 inches of water was sometimes required to overcome the resistance to the current in the workings.

Mr. RogEns remarked that there were several disturbing causes to be taken into consideration, and great precautions were necessary in ascertaining the vacuum correctly. The barometer showed 1 inch difference of height at the top and bottom of a deep shaft, such as that at Abercarn of 
nearly 900 feet depth, where it stood at 29 inches at the top, while it showed 30 inches at the bottom. The particulars of the height of the barometer and difference of temperature had been noted in his experiments, and were given in the table appended to the paper, together with the degree of vacuum arising from the natural ventilation due to the difference of temperature, which amounted to about $\frac{1}{7}$ inch of water.

Mr. SHELLEY enquired whether the distance of the fan from the pit mouth and its relative position were material for its good working.

Mr. Rogers said the distance of the fan from the shaft was immaterial, provided that the air passage from the pit to the fan was of the full size, free from contractions or obstructions. All that appeared requisite was to make the fan large enough to have an ample margin of surplus power of ventilation, without requiring a high speed of working; and from the results of his experience he should certainly recommend in future a considerably larger size of fan, probably as large as 21 feet in diameter.

Mr. HAwKes mentioned that a species of fan for ventilation had been tried many years ago by $\mathrm{Mr}$. Brunton, acting somewhat on the principle of a screw, to which allusion had been made; but he was not aware what results had been obtained with it. He remembered that Mr. Nasmyth had read a paper on the subject of ventilating fans at the meeting of the British Association at Ipswich several years ago, but thought the arrangement then proposed was different from that now deseribed.

The Chairman asked what was the construction of the ventilating fan at. Mr. Powell's colliery in South Wales, which was probably the one referred to as Mr. Brunton's, and whether it was at work now or had been given up.

Mr. Rogers replied that was the fan on Mr. Brunton's plan, and he remembered seeing it first put to work about nine years ago; it was a horizontal wheel about 9 feet diameter covering the top of the air shaft, with a large number of vanes set inclined like the vanes of a windmill or the blades of a screw; the air had access to the vanes on the underside, and was expelled from the upper side of the fan. The plan was found to be inperfect and unsatisfactory as a means of ventilation, and he believed it had been entirely abandoned. In the paper read before the British Association that had been referred to, Mr. Nasmyth proposed a fan only about $4 \frac{1}{4}$ or $4 \frac{1}{2}$ feet dinmeter, which was'so small a size that it would not liave at all answered the parpose. The large size of the present fan was 
the most important feature in the improvement, by which indeed the practical difficulties had been overcome. The whole credit of the calculations and arrangements in the form of the present fan was due to Mr. Nasmyth, and they were founded on the results of his experience; there might no doubt be many modifications of the form and proportions of the different parts of the fan, but these did not appear to be material points, and the simple construction that had been described appeared practically as good as any. He might mention that the plan had been thrown open by Mr. Nasmyth for general use, without reserving any exclusive right in it.

Mr. Cochrane thought a great feature in the plan of fan ventilation was the simplicity of the apparatus, and the smallness of cost, and also the applicability to deep mines; the great freedom from risk of derangement was an essential point, removing the objection ordinarily urged against ventilation by mechanical means. Any plan which tended to preserve life was of great value, and the fan ventilation was certainly an important step in the right direction; great credit was due to Mr. Rogers for investigating the subject so completely, and making such a thorough practical trial of the plan. There was no doubt this fan was doing the work of ventilation admirably, and he thought surpassing all other plans, and it required only to be better known to be extensively adopted; they were greatly indebted to Mr. Nasmyth for effecting this valuable improvement in the mode of ventilating mines.

Mr. Rogers observed that the power of suddenly increasing the current of air through the workings in any emergency was a great advantage over the ordinary furnace ventilation, in which no such change was practicable. He was convinced that the majority of deaths from explosions resulted from the suffocating effects of the after damp, and not from injuries occasioned by the explosion itself; and in cases where men recovered after an explosion, it was observed that a quantity of black carbonaceous matter, or "coal dust" as it was termed by the miners, was first thrown off the lungs; this was the result of the deposition of carbon in the atmosphere that had been inhaled; for every 45 volumes of fire damp, which was a mixture of carburetted hydrogen and air, produced in the explosion 2 volumes of vapour of carbon, which was precipitated in the form of minate black flakes filling the air. In the case mentioned in the paper, the result of suddenly turning the steam full on to the engine of the fan was remarkable; an immense volume of air, probably 70000 or 
80000 cubic feet per minute, instantly swept through the works like a hurricane, and carried off with it all the particles of carbon precipitated in the air. With the furnace however the ventilation might have been deranged by the explosion, and thus made worse instead of better at the very moment when most needed.

The ChaIRMan remarked that another advantage in the fan, that had not been directly alluded to, would be the uniformity with which the ventilation was constantly maintained; he had no hesitation in saying that the loss of life from bad ventilation was much greater than that from explosions, as the men working in the pit were exposed to bad air constantly, and the effects must tell seriously on their health when the ventilation was defective for any length of time, which was liable to be the case frequently with the ordinary mode of ventilation.

Mr. Ramsвotrom thought the fan an exceedingly perfect machine; the leading feature in the mechanical arrangement appeared to be the enlargement of the fan to a size admitting of direct action of the small steam engine by which it was driven, the engine working at the same speed as the fan, thus dispensing with any intermediate gearing, and reducing the whole to the simplest form of machine, which could be readily kept in good working order. A second cylinder might easily be applied if desired at the other end of the same shaft, which would render any stoppage from the failure of the working parts next to impossible.

The Chairman proposed a vote of thanks to Mr. Rogers for his paper, which was passed.

The following Paper, by Mr. William Waller, of Lincoln, was then read :- 
Hig. 1. Gemal Section of Pit and Fan.
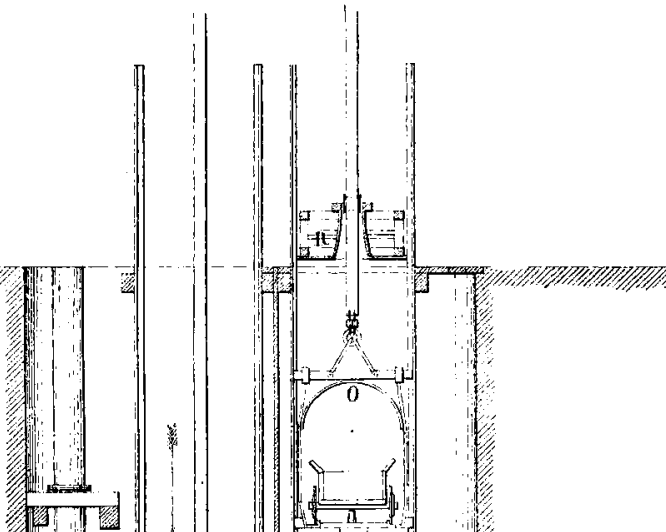

旁

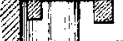

P

雅:

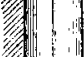

tis
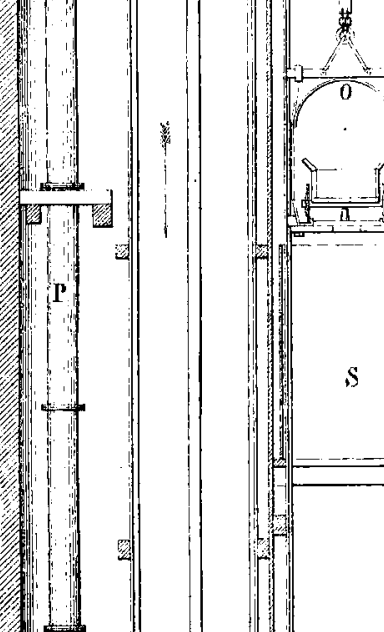

1.

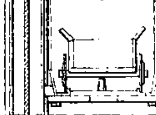

.

.
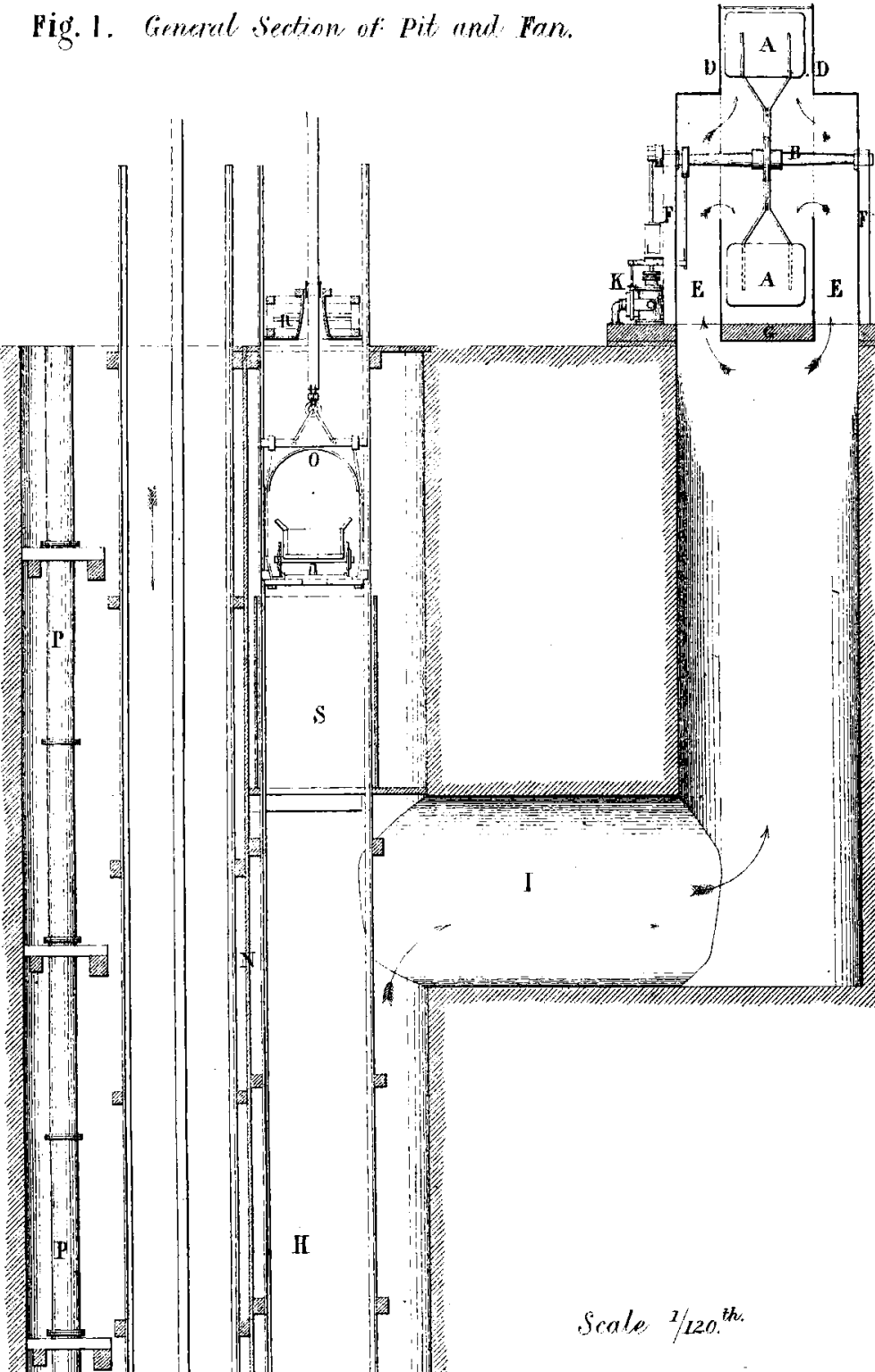

:

is.

4

得

H!

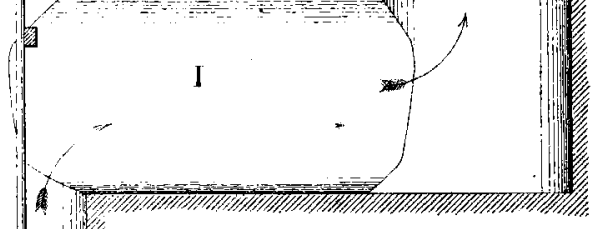

Scalo $1 / 20^{\text {th }}$

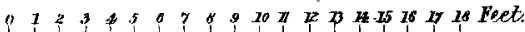


Fig. 2. Srction of Pit

showing Cage ascending.
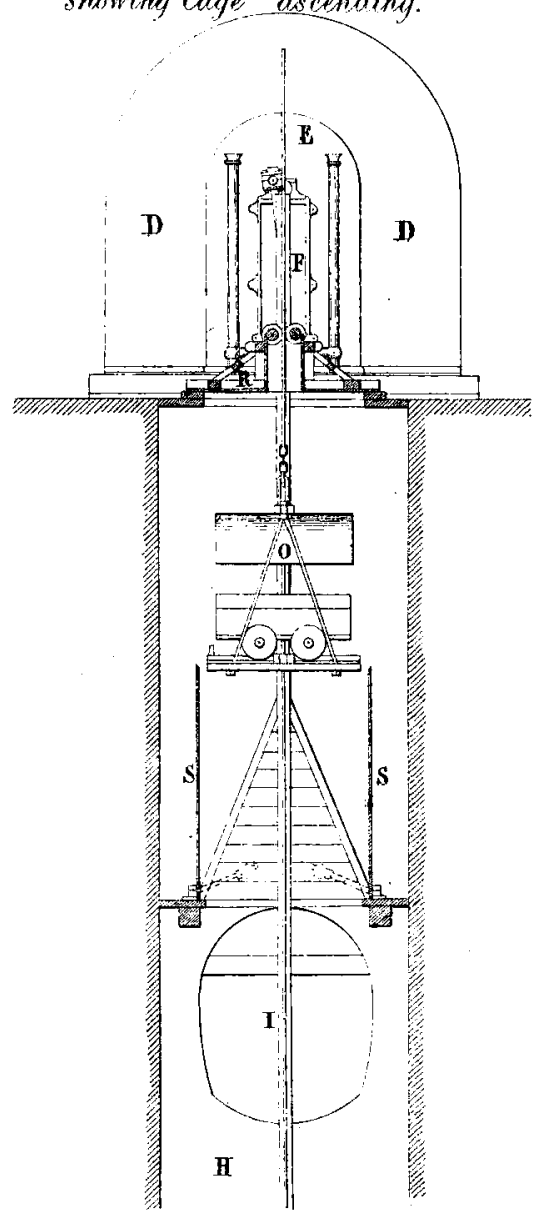

FAN.
Eig.3. Section of Pit Plate 8.9. showitg rage at top.
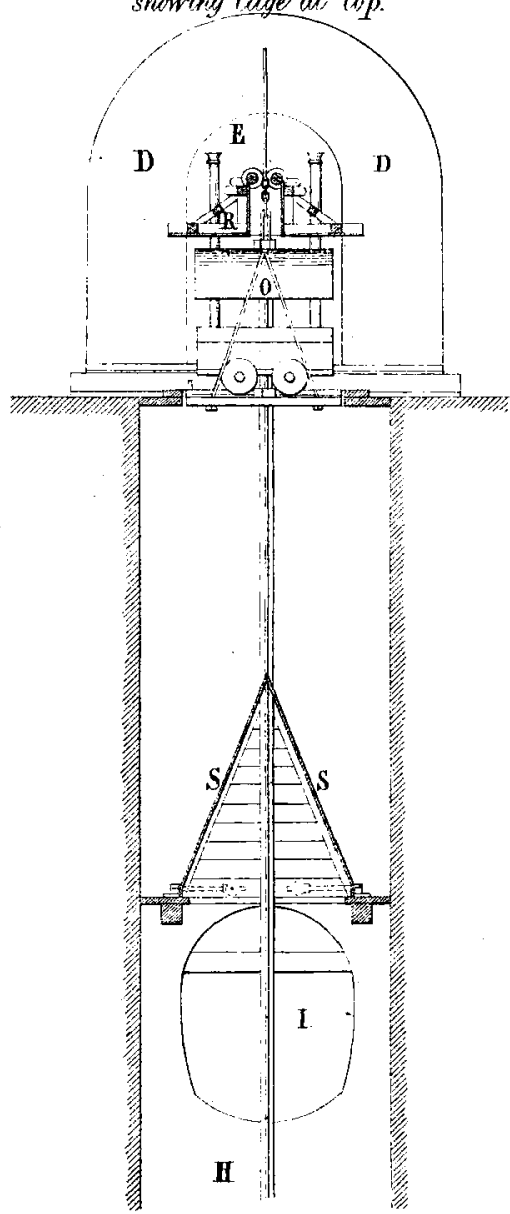

Fid. 4. Plan of Pit and Fans:

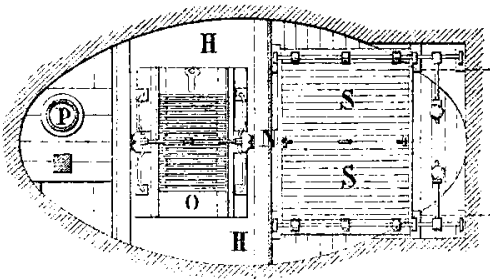

Sirester lizenth

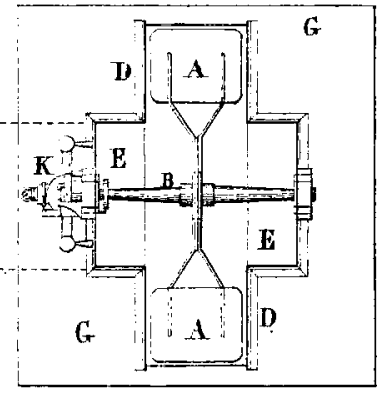

in Fert

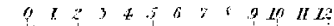

24

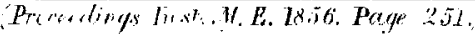

Downloaded from pme.sagepub.com at UNIV NEBRASKA LIBRARIES on June 5, 2016 


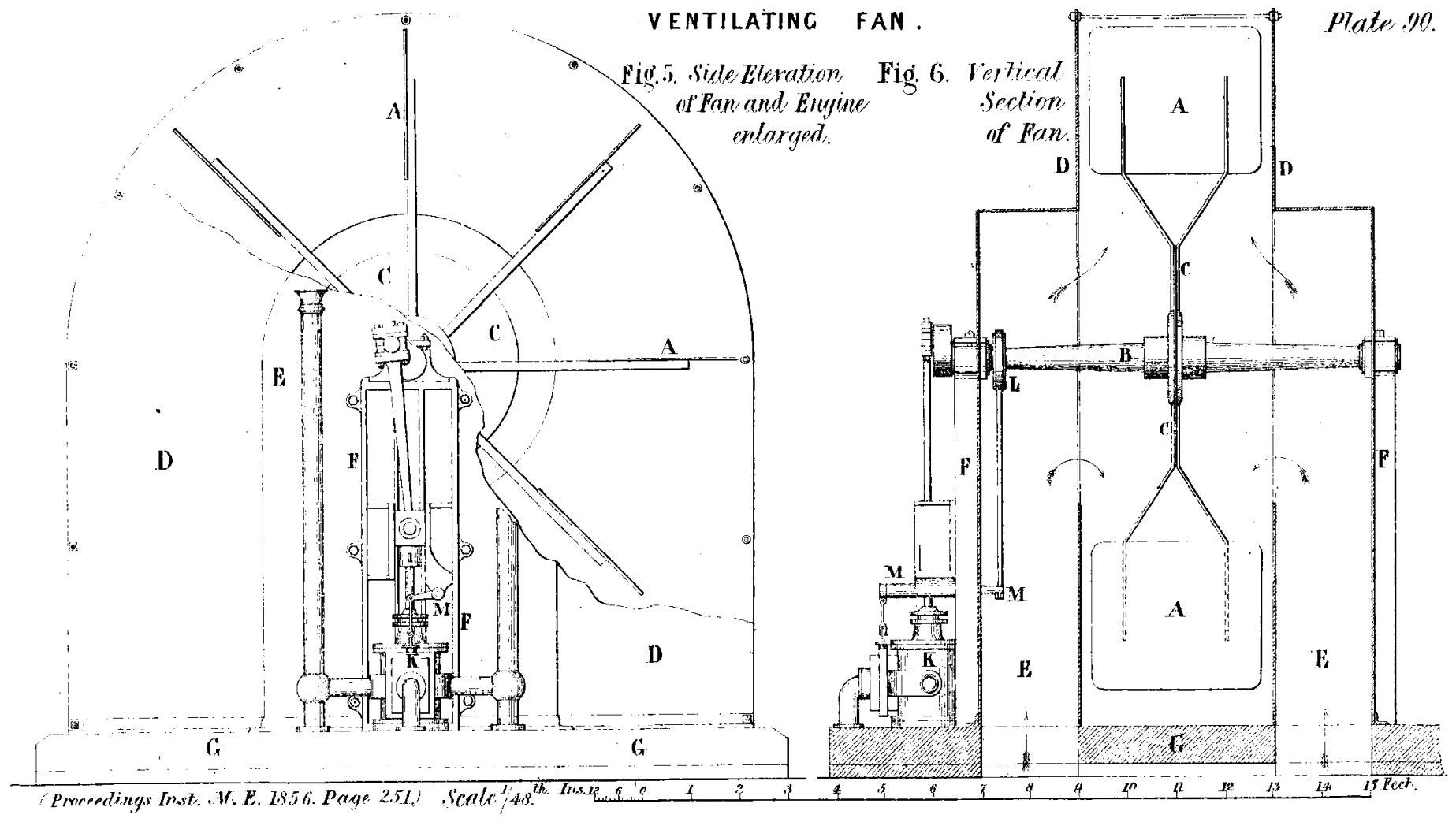

